\title{
AWL and ESP in the 21st Century: Crucial Ingredients in Non-English Speaking Scientific Communities
}

\author{
By Viviana Soler*
}

\begin{abstract}
The purpose of this paper is to present an overview of empirical data on the current scenario displayed by "writing literacy" in non-English-speaking scientific communities, particularly those in Latin America, taking into account the contributions of English for Specific Purposes (ESP) in relation to "writing literacy" in Europe, North America and Australia, in order to open an international debate on the need for writing/literacy teaching across ESP in Latin American universities and research centers. The issues emerging from this debate and those from local language audits will hopefully greatly contribute to: i) mapping ESP writing needs within the non-English-speaking academic and scientific community, and ii) redefining the scope of ESP should this be necessary. Reasons why focus is centered on this opportunity on "writing literacy" are given and indicators for measuring the identified needs are suggested.
\end{abstract}

Keywords: Academic writing literacy, Non-English-speaking scientific community, Scientific discourse

\section{Introduction}

To my surprise, I came to learn that at the 2007 Biophysical Society Annual Meeting held in Baltimore, MD, United States, the Committee for Professional Opportunities for Women sponsored a roundtable discussion on different topics, one of which was "grant-writing". During this roundtable discussion, two of its organizers claimed that although grant-application writing is a task that involves acquired skills that come from practice and experience, several scientists who have reached important hierarchical positions within their academic community have not had the opportunity to acquire such skills, yet they are expected to successfully compete for funding (Heidelberg and Harkins 2007).

My surprise was due to the fact that I understood -naively perhaps- that scientific societies are committed to encourage both science promotion and knowledge transference under the tacitly agreed assumption that writing literacy is a natural extension of scientific enquiry, thus it would appear to be unnecessary to provide scientists with tools to secure optimal scientific writing. Only after reading about this roundtable discussion did I realize that I was mistaken. The example about the Biophysical Society roundtable discussion on

\footnotetext{
* Certified Translator and Professor of English Language and Literature, Biochemical Research Institute of Bahia Blanca, National Council of Scientific and Technical Research (CONICETBahía Blanca), Southern National University (UNS), Argentina.
} 
grant-writing shows that science work is a chain of interrelated heterogeneous activities towards knowledge production and that such interrelated heterogeneous activities progress only if members of the scientific community have optimal linguistic literacy skills. The latter involve optimal linguistic literacy skills in writing and in speaking. For reasons of brevity, the focus of attention in the present work will be centered on literacy skills in writing only.

The above-mentioned example is also a clear indicator of the fact that reaching scientific recognition worldwide is not synonymous with having writing literacy skills. It also implies that science depends on a varied range of written genres and types of texts to accomplish its aims. These genres and text types could be divided, in principle, into two groups depending on the stage of progress of the scientific work, i.e. the "science-in-the-making" stage and the "ready-made science" stage, both being intricately interwoven through language in the "science-making" process. Grant-writing, for example, which belongs mainly to the science-in-the-making stage, is the regular practice -among scientists- of completing an application process for funding provided by an institution. Although grant proposals are an important routine of the professional writing of researchers and consume as much as a quarter of the time of a research group (Myers 1990, 1991) little research has been devoted to this genre (Myers 1990, 1991, Johns 1993, Connor and Mauranen 1999). Furthermore, in spite of the fact that grant-writing skills in science are crucial to guarantee funds for research, not all scientists are equally successful after a grant application. The major reason for this is that not all of them are naturally and equally equipped with the corresponding skills. Therefore, while the principles and fundamentals of grantsmanship apply broadly, it is important to know the target and to be able to tune the language appropriately. Understanding the creation process of a grant proposal is a big part of the success in grant-writing (Markel 2012).

On the other hand, the ready-made science stage involves a linguistically varied set of written genres which are mainly and straightforwardly related to the findings derived from science work, such as highly advanced scientific research papers and review papers. The categorization of other written genres, such as poster presentations for scientific meetings and $\mathrm{PhD}$. theses, seems to depend on the nature of the scientific results reported in terms of conclusiveness or non-conclusiveness. Thus, if results collected from a given research field are conclusive, they can be labeled as belonging to the readymade science stage whereas if they are not yet conclusive -although they do pave the way towards conclusiveness- they can be labeled as belonging to the science in the making stage. Although this distinction is external to language itself, it is a determining factor in the choice of linguistic strategies to communicate science and, in turn, in the development of high standards within the scientific community.

So far, this brief presentation on science work has been introduced taking into account variables (funds, aims and objectives, study design, etc.) that are outside the scope of language per se but are nevertheless central to language use. In parallel, another crucial point worthy of further analysis in relation to 
science work is: the language of science. It is an unquestionable truth worldwide that the language of science today is English, which generates -whether we like it or not- a division between the native English-speaking world and the non-native English-speaking world which, in turn, produces several other divisions (social, political, etc.) beyond the scope of language (Soler 2007). Within the framework of this division, in science in particular, native English-speaking scientists are better positioned for success in science communication than their non-English-speaking counterparts. Therefore, particularly among the latter, English for Specific Purposes (ESP) is crucial as it provides tools to help them compete with their English-speaking counterparts with linguistic proficiency, thus ensuring the capabilities necessary to reach academic writing literacy (AWL).

Thus, the purpose of this paper is to present an overview of empirical data on the current scenario displayed by writing literacy in non-English-speaking scientific communities, particularly those in Latin America, taking into account the contributions of ESP in relation to AWL in Europe, North America and Australia, in order to open an international debate on the need for writing/literacy teaching across ESP in Latin American universities and research centers. The next sections present respectively the analysis of some basic issues related to this article:

- ESP and AWL,

- ESP and AWL: how the same problem is approached by both the English-speaking scientific community and the non-English-speaking scientific community,

- benefits of ESP teaching and AWL within the Latin American scientific community,

- obstacles to ESP teaching and AWL development within the Latin American scientific community, and

- reasons for promoting AWL development through ESP.

\section{ESP and AWL}

The first point to analyze in this section deals with the meaning of literacy, which indicated familiarity with literature until late in the nineteenth century, when it came to designate abilities to read and write texts while conserving its wider meaning of being knowledgeable in a particular field (UNESCO 2006). Literacy has been defined as a continuum of learning through which individuals are trained to achieve their goals, to develop their capabilities and to participate fully in their community (UNESCO 2004, 2006). The word literacy belongs to a class of auto-positive terms, such as solidarity and cooperativism, among others, that are assumed to represent necessary and desirable attributes for our society, but when subjected to a thorough semantic and lexical analysis they become elusive, thus leading to a non-definite or simple definition (Venezky 1990). Nonetheless, it is important to bear in mind 
that the power of literacy, which is often underestimated, lies not only in the ability to read and write but also in the ability to put these skills to work in shaping the course of an individual's life. Thus, a broader concept of the term moves from a strict and appropriate language decoding and coding into issues not only of language but also of economics, health, and sustainable development (UNESCO 2006). This all-encompassing conception of literacy, transforms lives because literacy is a never-ending process in the life of individuals and it progresses through different levels, the majority of which are straightforwardly related to the ordinary levels of education in the life of human beings. Of all these levels, this article will focus on AWL, which is one of many kinds of literacies, and its relationship with ESP in science.

Academic literacy, which is directly related to higher education in a discipline-specific sense, has been found to be critical in fostering academic success (Yeld 2003). Based on the several definitions of academic literacy (Bharuthram and Mckenna 2006, Braine 2002, Brent 2005, Geisler 1992, Newman et al. 2003, among others), one that probably captures its essence is the one which defines it as a set of skills that university students and members of the scientific community must master in order to perform successfully as "scholars" (Henderson and Hirst 2007), i.e. ways of thinking, reading, speaking and writing in the scientific setting as well as ways of receiving, managing and creating knowledge for the benefit of a field of study.

In view of all the above, the first question that arises is: what is the relationship between ESP teaching and AWL? Firstly, in the world of science this relationship is a sine qua non condition to help science reach its goals. Secondly, as English has become the language of science all over the world, English teaching programs must be offered to the English-speaking scientific community as well as to the non-English-speaking scientific community to make literacy attainable for every member of the scientific community. Thirdly, the fact that science is the framework within which English is necessary to attain AWL, traditional English teaching or "English for no Obvious Reason teaching" (Abbott 1981: 228) is ineffective for science (Soler 2007). Viewed as an approach that belongs to the Language for Specific Purposes, ESP is thought to be unique as it is offered to both learners for scientific and academic purposes in educational institutions and experienced workers or professionals in the workplace to improve their communication skills. Of these two groups of learners, in science in particular, ESP operates as a specialized English language teaching tool in order to develop specific skills in response to a set of needs highlighted by all members of the scientific community, one of which is AWL.

On the other hand, Limbrick and Aikman (2005: 4) claim that the debate on the relationship between ESP and AWL has been "common in countries where English is an official language, such as Australia, England, Singapore and Canada, for the last two decades". The English-speaking scientific community is indeed aware of the need for its members and graduate and postgraduate students to develop academic literacy and proficiency in the language of delivery, i.e. English. In the past, although students entering 
universities or postgraduate students entering research centers were thought to be reasonably well-trained to carry out their studies, the general complaint from scientists was -and still is- that young fellows do not have the necessary writing skills to successfully complete their PhD. studies (Murray 2010). The picture is exactly the same in Latin American universities and research centers, where professors and scientists complain: "Students don't know how to write" (Carlino 2012). Therefore, although the scientific community is currently suffering from the same problem related to poor AWL skills all over the world, what are the differences between the measures taken to solve this problem by the English-speaking scientific community and those taken by the non-Englishspeaking scientific community to solve exactly the same problem? An answer to this question is attempted in the following section.

\section{ESP and AWL: How the Same Problem is approached by both the English-Speaking Scientific Community and the Non-English-Speaking Scientific Community}

Based on the Writing across the Curriculum/Writing in the Disciplines (WAC/WID) Mapping Survey (Thaiss 2012), the difference between how the English-speaking scientific community and the non-English-speaking scientific community, particularly that of Latin America, cope with the problem arising from poor AWL skills, lies in the fact that, Latin American universities and research centers are less involved institutionally not only in addressing this problem but also in delineating policies concerning academic writing teaching via ESP pedagogy (Soler 2004). Therefore, although it is not an intrinsically linguistic issue, this is an important obstacle that ESP must overcome in Latin American universities and research centers.

Another visible difference lies in the lack of autonomy in writing among graduate students and young generations of non-English-speaking scientists (Tanyeli and Kuter 2013), which is a natural consequence of the low number of institutional policies dealing with the problem arising from poor AWL skills in Latin American universities and research centers (Soler 2004). In contrast, in Europe, the United States and Australia, the problem exists but these areas offer an umbrella of institutional syllabuses either to solve it or attenuate it (Carlino 2004). The pillars upon which the institutional strategies followed in Europe, the United States and Australia rest are sustained on two main concepts related to writing, namely: i) writing is one of the most important cognitive activities through which the contents of a given field are learnt, and ii) every scientific discipline generates its own discursive strategies and codes which are under the control of those who have entered such fields of study (Carlino 2004, Russel 1997). Writing is therefore constitutive of the discursive strategies of every field of knowledge (Bojel and Hjortshoj 1984). These principles have led to two main pedagogical movements in English-speaking countries: a) writing across the curriculum, first conceived in the United Kingdom in the 1970s and later developed in the 1980s in the United States 
(Bazerman et al. 2005), and b) writing in the disciplines (WID) (Hillard and Harris 2003, Monroe 2003). Both movements foster the integration of teaching ESP writing into all disciplines in order to help learners think about conceptual contents and to help them decode and encode the discursive particularities of each field of knowledge.

The United States have proven to be an active scenario, with an array of attempts to address and readdress the problems deriving from poor AWL literacy and to institute reforms by changing ESP curricula and teaching practices. It took decades to reduce or otherwise reallocate the responsibility for providing instruction in writing to graduates, postgraduates and young researchers (see Blau's anecdotal and theoretical presentation of this problem, 2006). In the mid-sixties, several programs were launched on a compulsory basis to improve the standard of scientific writing (Woodford 1972). Since then this country has witnessed a rich variety of didactic enterprises moving in the same direction, such as (to mention just a few) the Princeton Writing Program, the Duke University Thompson Writing Program, the Pennsylvania University Writing Program, and the California State University Writing Program.

Australia has also identified problems arising from poor AWL skills and has addressed this complex issue by firstly carrying out research on the problem (Chalmers and Fuller 1996, Chanock 2003). In this geographical area, in particular, the fact that advanced undergraduate students, graduate students and young researchers write in order to be evaluated, led Australian researchers to focus their attention on the relationship between evaluation, writing and learning (Storch and Tapper 2002, Straub 1997, 2000, White 1994). Various models for the development of AWL are currently under scrutiny in Australia, but the broad trend appears to be towards considering this as a responsibility best addressed within the disciplines (Purser 2011).

European universities and research centers have also initiated research on AWL through ESP pedagogy, particularly in the last two decades, and have fostered the creation of writing centers which are coordinated by the European Writing Centers Association (WRCA), an official entity founded in 1998 to develop an academic infrastructure for European writing work and to assemble its institutions under one umbrella (http://www.europa-uni.de/en/struktur/zfs/ schreibzentrum). Europe is also the scenario of pioneering efforts towards WID, -citing only a few examples- by the FYGE5400 Academic Writing and Seminar Skills in Genetics 1 ECTS organized by Turku University Language Center (http://netiopsu.utu.fi) and the Professional Development Programme designed by the European Medical Writers Association (EMWA, www. ewma.org). All the above-listed examples which, for brevity, have been isolated as probably the most representative, are clear indicators of institutional endeavors to solve the problem of poor AWL skills through ESP pedagogy.

The scenario within the Latin American scientific community is different. It is different in the sense that whatever the efforts and measures to cope with poor AWL skills are, they must be carried out in English, a foreign language for Latin America. Therefore, for Latin American science to reach audiences from all over the world, both universities and research centers in this 
geographical sector must work hand in hand to delineate policies that guarantee proper AWL skills, a goal that could not be attained via traditional English teaching but only through ESP teaching and pedagogy.

\section{Benefits of ESP Teaching and AWL within the Latin American Scientific Community}

Within scientific environments in particular, ESP has in general developed as a tool to help undergraduate, graduate and postgraduate students and researchers to use English in a varied set of scientific contexts (Hyland 2006). It is therefore taught in different parts of the world and the specific characteristics of such contexts determine the type of instruction (DudleyEvans and St. John 1998). Based on the language in which these courses are taught, the following contexts could be identified: i) the context in which international students use English in English-speaking countries (United Kingdom, United States, Australia); ii) the context where education is offered in English while the local mother tongue is used for everyday life (Hong Kong, Singapore, etc.); iii) the context where some courses in tertiary education are taught in English, particularly in disciplines, such as engineering, medicine and science (Jordan); and iv) the context where education is imparted in the native language of the country and English is taught as a foreign language (DudleyEvans and St. John 1998). The latter case corresponds to Latin America (e.g. Chile, Perú, Colombia, Ecuador, Argentina, etc.). Interestingly, the Latin American scientific community offers a set of local advantages which could be institutionally and systematically exploited as a platform upon which to further determine ESP directions (Martinez 2012). The sections below describe the factors and advantages that help ESP pedagogy to be operative and to guarantee AWL-skills development to the scientific community (Martinez 2012).

Field-homogeneity

In Latin American universities and research centers, English is taught in compulsory courses belonging to undergraduate programs through which students share a particular field of study. This academic structure contributes in delivering ESP courses in field-homogeneous groups, which in turn becomes the ideal platform for ESP to be operative. In Argentine universities, for example, the majority of ESP programs are designed -though not all on a compulsory basis- for undergraduate, graduate and postgraduate students, taking into account their main fields of studies. This field homogeneity (Martinez 2012) is an element favoring ESP pedagogy in Latin American universities and research centers as it stimulates and guarantees the use of authentic scientific material. This, in turn, either attenuates or minimizes lexical problems, on the one hand, and activates disciplinary background knowledge on the other. 
Specificity

Those attending ESP courses in Latin American countries have urgent and very specific needs, a phenomenon which is advantageous to the organization of ESP courses because it is practical to concentrate on one particular teaching goal at a time, e.g. to focus attention on writing skills. ESP teaching programs in Argentine universities, for example, are able to balance this specificity as they develop reading in the undergraduate courses and writing in the postgraduate courses. This is possible only through organized specific teaching which requires, on the one hand, teachers of English with a sound knowledge of the genres and disciplines required, and learners concentrated on the genres their disciplines focus on (Martinez 2012, Soler 2004).

\section{Non-English-speaking Status}

Rather than being an obstacle, Latin America's non-English-speaking status is advantageous to ESP teaching to the scientific community. The fact that teachers of English at universities and research centers are Latinate language-speaking teachers, has the benefit of creating the opportunity of sharing the same language with learners. This, in turn, engenders a learnerteacher proximity which helps teachers focus on those linguistic issues that are problematic for Latinate language-speaking students, e.g. subject-verb agreement (Vigliocco et al. 1996), the syntax regime of English and Spanish (Whitley 2002), highly complex and long nominal groups (Soler and Vallejos 2013, 2011, 2014a), adjectivization (Soler 2002), textual authorial absence/ presence (Soler 2014b), etc., thus maximizing the course schedule.

\section{Latinate Background}

Latin America is embedded in a Latinate background on account of the fact that Spanish and Portuguese are the two major languages of Latin origin spoken in this part of the world. This is advantageous to ESP teaching within the scientific community as a result of the important influence of Latin on English, mainly in the field of scientific vocabulary. In this respect, Nation (2010) claims that the learning burden of vocabulary can be alleviated by "explicitly relating vocabulary to known items that are similar in either L1 or L2, by showing the patterns or rules in the first or second language, by showing the patterns or rules that the word fits into and by preteaching items and features that will make the new word easier to learn". Therefore, as scientific terms in English are expected to have their Spanish and Portuguese cognates, this linguistic similarity between local languages and English, in science, contributes to minimize the learning burden of specific scientific vocabulary. 


\section{Obstacles to ESP Teaching and AWL Development within the Latin American Scientific Community}

If all the above are advantages for ESP teaching in Latin America, and if there is an increasing demand for AWL development in this part of the world, why is it that ESP teaching progress mainly in relation to AWL is still so slow in some areas of this geographical area (e.g. Argentina, Colombia, Ecuador)? To our knowledge, a variety of reasons, mostly of non-linguistic nature, contributes to this, in particular:

1. Absence of institutional support for compulsory ESP teaching programs that promote $\mathrm{PhD}$ students' and young researchers' academic performance through the development of advanced AWL skills in scientific environments. An exception to this is the courageous project Programa de desarrollo de habilidades de lectura y escritura académica a lo largo de la carrera [Program for the development of academic reading and writing skills throughout a university career] whose origins go back to 2002 at the Universidad Nacional de General Sarmiento, Argentina (www.ungs.edu.ar).

2. Preliminary status of Latin American research on the relationship between ESP teaching and learning and AWL (with the exception of the fruitful work conducted by Dr. Paula Carlino in Argentina compared to the state-of-the-art in the same field in English-speaking scientific communities, mainly in the United Kingdom, the United States and Australia (Carlino 2005).

3. Disagreements on who must be responsible for the ESP teaching courses designed particularly for the scientific community, i.e. should it be a teacher of English, should it be a researcher on discourse analysis, should it be a specialist in each scientific discipline/field, or should it be a combination of some of these alternatives?

4. Presence of a linguistically more complex scenario for ESP pedagogy as a result of the co-existence of poor AWL skills in English as well as in the native languages of Latin America.

5. Little or no interaction at all among ESP teachers, researchers of scientific and academic discourse and specialists in each scientific discipline/field which, in turn, generates isolated, instead of integrated instances of joint-work towards the same aim.

6. Absence of systematic training in ESP in scientific writing on a compulsory basis at the postgraduate level, thus preventing the collection of empirical data that may help design further policies to deal with the problem.

7. Presence of an enormous gap in terms of writing training between a student entering the university education system and a full-time fellow or young researcher in the scientific system. The gap is so big that it favors the co-existence of sub-target groups, each with individual and very specific needs. 
8. In line with (7), the presence of a complex audience requiring ESP courses to attain AWL as a result of the co-existence of four completely different groups, namely: the group of graduate students, the group of postgraduates (mainly $\mathrm{PhD}$ students), the group of fellows and young researchers at research centers, and the group of scientific text-revisers and editors of scientific journals, each with individual and very specific needs.

9. Absence of a conception of AWL as a continuum from short writing excerpts as practised at high school level to a variety of genres and texttypes at the highest levels of university education and scientific life.

10. Although all the above are non-linguistic items (and are therefore outside the scope of English language per se), they are, in our view, obstacles to the systematization of ESP teaching in Latin America.

Two further reasons why ESP teaching evolution in relation to AWL skills within the Latin American scientific community is so slow concern -in our view- language directly. One of them is related to a widely spread misconception of what writing is, namely that it is a universal means for the recording and transmission of knowledge (i.e. grammar and spelling) instead of being looked at as an epistemic instrument which contributes to constructing knowledge and which varies according to the regular practices of each field of knowledge (Carlino 2012). Unfortunately, this misconception is widespread at the graduate and postgraduate level in Latin America.

In line with this, of the four groups listed in item (8) above, the group that has almost no training in academic writing is, in our view, that of postgraduates. In most Latin American countries, postgraduate studies are carried out firstly through a licentiate degree and subsequently through a $\mathrm{PhD}$ degree, both involving a thesis written in Spanish. This generates a two-fold problem. One derives from the lack of a culture of AWL in science as a result of the absence of systematic institutional policies fostering the development of AWL. Postgraduates are supposed to be prepared to write a PhD thesis in their mother tongue while reality shows the opposite on account of the fact that they are not taught how to do so (Carlino 2004, 2005). The other problem refers to the influence that the English language exerts on Spanish $\mathrm{PhD}$ thesis prose as most scientific literature used by postgraduates to complete their theses is in the English language. Spanish prose in $\mathrm{PhD}$ theses is affected by the transference of grammatical structures that are characteristic of highly advanced scientific discourse. Some instances are, at a grammatical level, the transference to Spanish of the English "zero article"; at an orthographic level, the transference of incorrect spellings, such as "proteina" instead of the correct spelling "proteína"; at a lexical level, the presence of anglicisims that may not be accepted in Spanish, such as "altamente" for "highly"; etc. Likewise, while English affects Spanish prose at the postgraduate level, Spanish affects English prose once postgraduates become members of research centers (E. Camadro, personal communication, April 9, 2014). Unfortunately, AWL is taken for granted in Latin American universities and scientific centers. Actually, 
postgraduates are not trained in any compulsory course in writing a $\mathrm{PhD}$ thesis in their mother tongue, nor are postdocs and young researchers trained in writing research papers, review papers, posters, abstracts, etc. in English. Thus, thesis writing and research paper/abstract/poster writing are the most immediate writing needs for postgraduates and fellows and young researchers, respectively, in Latin America.

The other reason why ESP teaching evolution in relation to AWL skills within the Latin American scientific community is so slow, is the fact that little is known in terms of practice about the ability of English-speaking and nonEnglish-speaking graduates, postgraduates and young scientists to "technicalize" in order to create chains of reasoning in their writings (Soler 2004). This is an important gap that involves both the English-speaking and the non-English-speaking scientific community (the former to a lesser extent than the latter) and therefore needs to be addressed by ESP researchers and practitioners.

\section{Reasons for Promoting AWL Development through ESP}

To begin with, writing is the means through which experiments, analyses, inferences, hypotheses, methods followed, results, discussions, etc. are reported in science. Its prevalence with respect to speaking in non-English-speaking scientific communities lies in the fact that non-English-speaking scientists may not be able -for several reasons- to report their discoveries orally, while they will certainly be able to do so either on their own or with the assistance of text revisers through their texts written in English (Soler 2009). Thus, writing rather than speaking in science is the bridge that joins non-English-speaking scientists with their English-speaking counterparts. In addition, correct written formulation of scientific claims is also a sine qua non condition at the sciencein-the-making stage as well as at the ready-made science stage. The urgent need to write in English also increases at an ever-growing pace as more and more Latin American scientists take part in joint research projects with English-speaking scholars (ERASMUS, NIH, EULANEST, ABEST, etc.) all over the world. Such cooperation involves different written texts belonging either to the science in-the-making stage or the ready-made science stage, such as CVs, research applications, grant applications, progress reports, correspondence, research papers, review papers, etc. Therefore, everyone interested in selling Latin American science in the English-speaking scientific community does acknowledge the need for systematic training to attain AWL. In view of this, attainment of AWL is a necessity that ESP teaching must fill in the Latin American scientific community. 


\section{Conclusion}

The purpose of this paper was to present a summary of empirical data on the current scenario displayed by AWL in non-English-speaking scientific communities in Latin America, and, taking into account the contributions of ESP in relation to writing literacy in Europe, North America and Australia, to reflect on the need for writing/literacy teaching across ESP in Latin American universities and research centers. Based on the "X-ray of AWL" within the Latin American scientific community briefly outlined in this paper, the following conclusions can be drawn:

a) from the well-known opposition between traditional/general English teaching or "more disparagingly 'English for no Obvious Reason' teaching" (Abbott 1981, Belcher et al. 2011) and ESP teaching, it follows that ESP is the ideal approach to attain AWL in the Latin American scientific community. This is because, compared to the "more disparagingly 'English for no Obvious Reason' teaching", ESP is based on a prior analysis of learners' specific communicative needs and focuses on the acquisition of highly specialized scientific lexicon and awareness and command of different scientific genres.

b) ESP recognition that: i) writing and literacy are specific to disciplines, and that ii) linguistic variation occurs not only across disciplines and professions but also across genres within them, is a sine qua non condition to make ESP pedagogy effective in science.

c) The following further urgent actions within the field of ESP are certainly necessary to capitalize on its efforts towards the attainment of AWL, in particular:

i. Strong and permanent interaction among English for Academic Purposes researchers, teachers of English, ESP practitioners, epistemologists and experts in all scientific disciplines.

ii. Strong and permanent interaction with psycholinguists to make AWL development through ESP pedagogy an integral part of the academic acculturation process.

iii. Design of didactic procedural models for ESP conceptions of AWL development in order to come to terms with the challenges posed by critical perspectives of literacy and teaching. Compared to empirical and theoretical ESP research on discipline-specific writing, much less study has been devoted to date to the design of practical academic writing activities to develop the ability to "technicalize", i.e. to raise awareness of the linguistic resources through which either concepts or words are embedded in a body of knowledge.

iv. In line with (iii) a pending task for ESP practical pedagogy and AWL development in non-English-speaking environments, especially in Latin America, is to identify the discipline discourse clues used by scientists to signal varying degrees of technicality and 
to compare and contrast written patterns of scientific discourse centering on specific variables, mainly student vs. expert scientific writing, native vs. non-native scientific writing and disciplinespecific forms of technicality in the English-speaking scientific community vs. discipline-specific forms of technicality in the nonEnglish speaking scientific community.

v. In line with (iv) another pending task to foster AWL through ESP practical pedagogy in non-English-speaking communities is to differentiate the writing comfort zone of scientists and postgraduates (Salvador 2015) from the writing non-comfort zone and to train how to exploit both through practical activities. To this end, psycholinguistics will be of invaluable assistance.

\section{Acknowledgements}

Thanks are due to Dr. Patricia Vallejos from the Departamento de Humanidades, Universidad Nacional del Sur (UNS), Argentina, for her comments, cooperation, and guidance in the present article. This work was supported by grant PGI 24/I205 from UNS to Dr. P. Vallejos, director of the project "Textual aspects of scientific knowledge", within which this contribution was prepared. Thanks are also due to anonymous Referees for their useful comments and suggestions which have greatly improved the quality of my manuscript.

\section{References}

Abbott G (1981) Encouraging communication in English: A paradox. ELT Journal 35(3): 228-230.

Bazerman C, Little J, Bethel L, Chavkin T, Fouquette D, Garufis J (2005) Reference guide to writing across the curriculum. West Lafayette, Indiana: Parlor Press.

Belcher D, Johns AM, Paltridge B (2011) New Directions in English for Specific Purposes Research. Arbor, MI: University of Michigan Press.

Bharuthram S, Mckenna S (2006) A writer-respondent intervention as a means of developing academic literacy. Teaching in Higher Education 11: 495-507.

Blau S (2006) College writing, academic literacy, and the intellectual community: California dreams and cultural oppositions. In P. Sullivan and H. Tinberg (Eds.), What is College Level Writing? NCTE.

Bojel F, Hjortshoj K (1984) Composition theory and the curriculum. In F. Bogel \& K. Gottschalk (Eds.), Teaching Prose. A guide for Writing Instructors (pp. 1-19). New York: Norton.

Braine G (2002) Academic literacy and the nonnative speaker graduate student. English for Specific Purposes 1: 59-68.

Brent D (2005) Reinventing WAC again: The first-year seminar and academic literacy. College Composition and Communication 57: 253-276.

Carlino P (2012) Who takes care of writing in Latin American and Spanish universities? In Ch Thaiss, G Bräuer, L Ganobsik-Williams and A Sinha (Eds.), 
Writing Programs Worldwide: Profiles of Academic Writing in Many Places (pp. 485-498). Perspectives on Writing Series. Fort Collins Colorado: Parlor Press and the WAC Clearing House.

Carlino P (2005) Escribir, leer y aprender en la Universidad. Una introducción a la alfabetización académica (Write, read and learn in college. An introduction to academic literacy). Buenos Aires, Argentina: Fondo de Cultura Económica.

Carlino P (2004) Culturas académicas contrastantes en Australia, EE. y Argentina: Representaciones y prácticas sobre la escritura y sobre la supervisión de tesis en el grado y el posgrado universitarios (Contrasting academic cultures in Australia, USA. UU. and Argentina: Representations and practices on writing and on monitoring the degree thesis and graduate university). Conference Paper. Int. Meeting "Mente y Cultura: Cambios representacionales en el aprendizaje", Centro Regional Universitario Bariloche, Universidad Nacional del Comahue, Bariloche, Argentina, 11-13 February.

Chalmers D, Fuller R (1996) Teaching for learning at University. London: Kogan Page.

Chanock K (2003) Autonomy and responsibility: same or different? In H Reinders, J Jones-Parry, H Anderson, M. Hobbs (Eds.), Supporting Independent Learning in the $21^{\text {st }}$ century. Proceedings of the inaugural conference of the Independent Learning Association, University of Melbourne, Australia, 13-14 September.

Connor U, Mauranen A (1999) Linguistic analysis of grant proposals: European Union Research Grants. English for Specific Purposes 18: 47-62.

Dudley-Evans T, St. Johns M (1998) Developments in ESP: A multidisciplinary approach. Cambridge: Cambridge University Press.

Geisler Ch (1992) Exploring academic literacy: An experiment in composing. College Composition and Communication 43: 39-54.

Heidelberg R, Harkins A (2007) Grant-Writing tips. Biophysical Society Newsletter September/October: 20-21.

Henderson R, Hirst E (2007) Reframing academic literacy: Re-examining a short course for "disadvantaged" tertiary students. English Teaching: Practice and Critique 6: 25-38.

Hillard V, Harris J (2003) Making writing visible at Duke University. Peer Review (Autumn): 15-17.

Hyland K (2006) English for Specific Purposes: some influences and impacts. In A Cummins, and $\mathrm{C}$ Davison (Eds.), The international handbook of English language education (pp. 379-390), Vol. 1, Norwell, Mass: Springer.

Johns AM (1993) Written argumentation for real audiences: suggestions for teacher research and practice. TESOL Quarterly 27: 75-90.

Limbrick L, Aikman M (2005) New times: the place of literacies and English in the curriculum. Curriculum Matters 1: 29-48.

Markel M (2012) Technical Communication, 10th Edition. Retrieved from: https://goo.gl/MfETfi.

Martinez I (2012) English for academic purposes in Latin América: Advantages of the context. ARTESOL Eng. Specific Purp. Interest Section, ESP E-j. 2: 3-5.

Monroe J (2003) Writing and the disciplines. Peer Review (Autumn): 4-7.

Murray J (2010) Memories of MENAWCA 2009. News from the Centers 2(1): 3. Retrieved from www.menawca.org

Myers G (1990) Writing biology: texts in the social construction of scientific knowledge. Madison, WI, USA: University of Wisconsin Press.

Myers G (1991) Conflicting perceptions of plans for an academic centre. Research Policy 20: 217-235. 
Nation P (2010) Learning second language vocabulary. In M Berns (Eds.), Concise Encyclopedia of Applied Linguistics (pp. 200-206). Oxford: Elsevier.

Newman M, Trenchs-Parera M, Pujol M (2003) Core academic literacy principles: a multi-case study of academic achievement. English for Specific Purposes 22: 4571.

Purser ER (2011) Developing academic literacy in context trends in Australia. In M Deane, and P O'Neill (Eds.), Writing in the Disciplines (pp. 30-43). New York: Palgrave Macmillan.

Russel D (1997) Writing and genre in higher education and workplaces: A review of studies that use cultural-historical activity theory. Mind, Culture and Activity 4(4): 224-237.

Salvador G (2015) Personal Communication.

Soler V (2002) Analysing adjectives in scientific discourse: An exploratory study with educational applications for Spanish speakers at advanced University level. English for Specific Purposes 21: 145-165.

Soler V (2004) English in the world of science. II Congreso para Profesores y Estudiantes de Inglés. Bahía Blanca, Argentina, 9-10 July.

Soler V (2007) Simbiosis de lo lingüístico y lo no-lingúistico en la formación del traductor científico (Symbiosis of the linguistic and non-linguistic training in scientific translator). Traduçao e Comunicaçao, Revista Brasileira de Tradutores 16: $91-100$.

Soler V (2009) Anecdotario y reflexiones de un traductor en el sistema científico argentino (Anecdotes and reflections of a translator in the Argentine scientific system). V Jornadas de la Escuela Superior de Idiomas (ESI), Universidad Nacional del Comahue, General Roca, Argentina, 17-18 October (Read in absentia).

Soler V (2011) Comparative and contrastive observations on scientific titles written in English and Spanish. English for Specific Purposes 30: 124-137.

Soler V, Vallejos P (2013) Reflections on the challenging issues posed by highlyadvanced scientific nominal group titles. Olomouc Linguistics Colloquium Olinco 2013, Olomouc, Czech Republic, 6-8 June. Abstract Book pp. 156-157.

Soler V (2014a) Highly advanced scientific titles in the field of reading pedagogy. Revista de Investigación e Innovación en la Clase de Idiomas 23: 142-151.

Soler V (2014b) Scientific Communication and the Nature of Science: An illustration of oscillations from researcher's proximity to researcher's distance in scientific titles and its pedagogical implications. Colombian Applied Linguistics Journal 16(2): 291-302.

Storch N, Tapper J (2002) A useful kind of interaction? Evaluations by university students of feedback on written assignments. Australian Review of Applied Linguistics 25(1): 147-167.

Straub R (1997) Student's reactions to teacher comments: An exploratory study. Research in the Teaching of English 31(1): 91-119.

Straub R (2000) The student, the text and the classroom context: A case study of teacher response. Assessing Writing 7: 23-55.

Thaiss Ch (2012) Chapter 1: Origins, aims and uses of writing programs worldwide: Profiles of academic writing in many places. In Ch Thaiss, G Bräuer, L Ganobsik-Williams, and A Sinha (Eds.), Writing Programs Worldwide: Profiles of Academic Writing in Many Places (pp. 5-22). Perspectives on Writing Series. Fort Collins Colorado: Parlor Press and the WAC Clearing House.

Tanyeli N, Kuter S (2013) Examining learner autonomy in foreign language learning and instruction. Eurasian Journal of Educational Research 53A: 19-36. 
UNESCO - United Nations Educational, Scientific and Cultural Organization Position Paper (2004) The plurality of literacy and its implications for policies and programs. Retrieved from: http://goo.gl/ONCG0P.

UNESCO - United Nations Educational, Scientific and Cultural Organization (2006) Chapter 6: Understandings of Literacy. In Education for All Global Monitoring Report. Paris, France.

Venezky R (1990) Definitions of literacy. In: R Venezky, D Wagner, B Ciliberti (Eds.), Toward Defining Literacy (pp. 2-16). Newark, DE: International Reading Association.

Vigliocco G, Butterworth B, Garrett MF (1996) Subject-verb agreement in Spanish and English: Differences in the role of conceptual constraints. Cognition 6: 261298.

White EM (1994) Responding to Student Writing. In Teaching and Assessing Writing $\left(2^{\text {nd }}\right.$ ed., pp. 103-118). San Francisco, CA: Jossey-Bass Higher and Adult Education Series.

Whitley MS (2002) Spanish/English contrasts: a course in Spanish Linguistics (2 $^{\text {nd }}$ ed.), Washington, DC: Georgetwon University Press.

Woodford FP (1972) Experiences in teaching scientific writing in the USA. Journal of Biological Education 6: 9-12.

Yeld N (2003) Academic literacy and numeracy profiles: An analysis of some results from the AARP and TELP tests of incoming students (2001/2002 entry years). In Into higher education - Perspectives on entry thresholds and enrolment systems. A joint SAUVCA-CTP pu 